\title{
Psychophysiological and Specific Fine Motor Skill Modifications in a Checkpoint Action
}

Joaquín Sánchez-Molina, José J. Robles-Pérez, Vicente Javier Clemente-Suárez

\section{Abstract}

In last years, the insurgency attacks on task forces bases and checkpoints have been common. The study of psychophysiological response of soldiers in these asymmetrical and non-controlled situations remains a challenge. The present research aimed to analyze the psychophysiological response and the variations in specific fine motor skill after a checkpoint simulation which included surveillance, unexpected attacks, and melee combat. Psychophysiological parameters -heart rate, blood glucose, pressure, oxygen saturation, and lactate, legs' strength, skin temperature, cortical activation, anxiety-, as well as fine motor skills were analyzed in a sample of 24 professional Spanish Army soldiers $(35.67 \pm 6.62$ years, $177.21 \pm 7.37 \mathrm{~cm}, 82.29 \pm 11.02 \mathrm{~kg}, 26.17 \pm 2.82 \mathrm{BMI}, 15.25 \pm 7.44$ years of experience in their unit) before and after a checkpoint simulation. The checkpoint surveillance operation produced a significant increase $(p<0.05)$ in rated perceived exertion, heart rate, blood lactate concentration, legs' strength and somatic anxiety, and a significant decrease in blood oxygen saturation and skin temperature values. We concluded that results were consistent with an activation of sympathetic nervous system, triggering a fight-flight response, a chain of intense psychophysiological reactions and a misinterpretation of perceived exertion. Results may help predicting soldiers' physical and operative behavior in real situations.

Keywords:

Psychophysiology, Lactate, Stress, Anxiety, Military 